AAUTORA

Maria Cristina Castilho Costa

Professora Livre-Docente do Departamento de

Comunicações e Artes da ECA-USP.

E-mail: criscast@usp.br

\title{
EDUCAÇÃO A DISTÂNCIA - ENTRE O ENTUSIASMO E A CRÍTICA
}

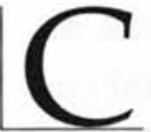

hamamos de educação a distância a metodologia de ensino utilizada para que conhecimento, atitudes e comportamentos sejam desenvolvidos em grupos de pessoas distantes que se comunicam apenas, ou preferencialmente, através dos meios de comunicação de massa. Há décadas que o correio, o rádio, a televisão e o vídeo têm sido utilizados com essa finalidade, em todo o mundo, tanto nos processos de educação formal como informal. Essas iniciativas têm mostrado sua capacidade para levar conhecimento a pessoas sem acesso a ele, quer por estarem distantes dos centros educativos, quer por não disporem de recursos e tempo para se deslocarem até eles. As experiências desenvolvidas com maior ou menor êxito têm deixado evidente, entretanto, as gran- des limitações das mídias analógicas para essa finalidade, principalmente em razão da baixa interatividade que faz da comunicação uma via quase que exclusivamente de mão única que vai do educador ao aprendiz. Essa unidirecionalidade impede a troca e o diálogo, elementos fundamentais do processo de aprendizado. Outra dificuldade dessas metodologias de ensino é a ausência de contato constante entre os alunos integrados pelos programas que se baseiam no uso do rádio ou da televisão.

Por isso o advento dos computadores e da comunicação em rede ${ }^{1}$ e a possibilidade de usá-los no ensino/aprendizagem tem tornado as demais tecnologias limitadas e obsoletas, a ponto de a educação a distância tornar-se quase sinônimo de educação por computador. Muitas têm sido as ferramentas

1. Desde a década de 1960 os cientistas norte - americanos estudam a possibilidade de vários computadores trabalharem em conjunto. A primeira rede criada foi a WAN - Wide Área Network. A Internet viria anos depois. As primeiras redes eram ligadas por linhas telefônicas, mais tarde foram utilizados cabos e satélites. 
desenvolvidas com essa finalidade como CD-ROMs ${ }^{2}$, bancos de dados, softwares ${ }^{3}$ educativos, sites ${ }^{4}$ especializados, jogos e simuladores e até o campeão de uso na rede que é o e-mail ${ }^{5}$. Nem todos esses recursos são de comunicação simultânea ${ }^{6}$ ou interativa, mas as possibilidades de um relacionamento direto entre professor e aluno e entre os alunos entre si para trabalhos coletivos deixa otimistas os mais ferrenhos críticos da educação a distância. As experiências mais bem sucedidas são aquelas que tentam integrar algumas dessas tecnologias educativas em processos que combinam a comunicação off-line e on-line ${ }^{7}$, sincrônica e assincrônica.

Algumas das ferramentas mais desejadas e desafiantes, todavia, são aquelas que colocam em contato professores e alunos de forma sincrônica e interativa com os recursos de som e imagem - recriando o contato pessoal, ainda que mediado pelo computador, tão característico da educação presencial. São elas as vídeo e teleconferências que introduzem na relação comunicativa um forte sentido de presença.

Chamamos de videoconferência a comunicação que se estabelece entre pessoas através de computadores ligados em rede, aos quais estão acopladas câmeras digitais, monitores de televisão e microfones, possibilitando a transmissão de imagens fixas e em movimento, além de sons, através de uma relação interativa que permite o diálogo entre os interlocutores. A videoconferência distingue-se da teleconferência por utilizar um aparato tecnológico mais simples e por envolver platéias menores que dificilmente ultrapassam o número de quarenta a cinqüenta pessoas. As teleconferências destinam-se a um público que pode chegar a centenas de pessoas e que, portanto, possibilitam muito pouca interatividade.

Tanto na videoconferência como na teleconferência, as linguagens oral e gestual são muito importantes, ao contrário de fóruns, chats $^{8}$ e $e$-mails que fazem uso, principalmente, do texto escrito.

\section{WORKSHOP DE VIDEOCONFE- RÊNCIA}

Minha experiência com vídeo e teleconferências era pequena quando

2. CD-ROM é a sigla de Compact Disk - Read Only Memory - designaçâo de discos ópticos graváveis a laser, uma única vez.

3. Software é o nome genérico de programas que instruem os computadores para todo tipo de ação desde editores de texto até ligaçôes em rede.

4. Sites ou sítios são domínios ou endereços de computadores remotos ligados à rede Internet.

5. E-mail é a abreviatura de eletronic mail ou correio eletrônico, o primeiro serviço instalado por redes de computadores.

6. Comunicação simultânea em meios digitais é aquela $\mathrm{em}$ que duas ou mais pessoas conectam-se à rede ao mesmo tempo, podendo desenvolver tarefas em conjunto, de jogos a trabalhos em grupo.

7. Diz-se que uma comunicação é on-line quando se dá por computadores conectados à redes. O computador está off-line quando trabalha isoladamente, desconectado de qualquer rede.

8. Chat ou conversa, em português, é o nome de um serviço disponibilizado na Internet que permite aos usuários trocar mensagens escritas em tempo real. 
participei da Conferência Anual da Associação de Centros de Ciência e Tecnologia ${ }^{9}$, realizada na cidade de Charlotte, na Carolina do Norte (USA), em 2002. Embora pequena, essa experiência trazia-me à memória grandes dificuldades técnicas na tentativa de colocar em contato pessoas ligadas a terminais remotos. Sistemas claudicantes e imagens com baixo grau de resolução tornaram maçantes as palestras on line a que eu havia assistido. Em razão disso, inscrevi-me em um workshop de educação a distância através de videoconferência - interessava-me saber como se resolviam as questões técnicas, comunicativas e pedagógicas.

O workshop ${ }^{10}$, oferecido pelo Museu de História Natural da Carolina do Norte, teve como coordenadoras Liz Baird, especialista em educação a distância, e Mary Ann Brittain, diretora do Programa Educativo do Museu. Cerca de quarenta alunos estavam inscritos e preparavamse para uma aula sobre História Natural.

Fomos encaminhados para uma sala com cadeiras que se dispunham de forma irregular, permitindo que formássemos pequenos grupos sem grandes transtornos. Fomos recebidos por Mary Ann que nos aguardava acompanhada por um técnico responsável pelas instalações. Ao centro e à frente de nós havia um monitor de vídeo de 29 polegadas e acima dele uma câmera pela qual nossa imagem era transmitida ao laboratório do Museu, onde
Liz Baird nos observava através da tela de seu microcomputador.

No monitor aparecia uma mulher de cerca de quarenta anos, bem apessoada e que nos sorria da tela, agradecendo nossa presença. Estava em pé e tinha à sua frente uma mesa com um computador na qual apoiava as mãos. No canto da tela abria-se uma pequena janela onde podíamos ver as imagens de nossa própria sala, tal como eram transmitidas para o Museu. Acomodamo-nos nas cadeiras formando círculos de maneira a podermos olhar o vídeo que passava a ser nosso centro de atenção, como a cátedra nas salas de aula convencionais. Lá podíamos assistir à professora e à nossa performance transmitida no canto inferior da tela.

Liz Baird se apresentou e, sempre sorrindo, incumbiu-nos de nossas tarefas - cada grupo recebeu de Mary Ann a reprodução de um animal (inseto ou réptil) em plástico ou cera e um texto no qual havia informações a seu respeito. A professora pediu que inicialmente contássemos para os demais integrantes do grupo o que sabíamos a respeito daquele espécime e que, depois, lêssemos o texto em busca de mais informações científicas.

Para o nosso grupo coube uma enorme e bonita borboleta amarela e preta, presa em uma caixa de vidro. Conversamos sobre sua aparência, tamanho e forma e contei a meus colegas norte-

9. A Association of Science-Technology Centers Incorporated - ASTC é uma organização sem fins lucrativos que reúne centros de pesquisa e museus com o objetivo de difundir a ciência para diferentes públicos. Fundada em 1973, a ASTC possui 583 membros em 42 países. Anualmente realiza encontros internacionais reunindo seus membros que apresentam trabalhos a toda a comunidade científica. Em 2002, a Conferência Anual realizou-se na cidade de Charlotte, capital do estado norte-americano da Carolina do Norte, entre os dias 12 e 15 de outubro.

10. O workshop Distance Learning from museums: using hands-on materials in videoconferencing ocorreu no dia 14 de outubro, no Bell South Building, em Charlotte. 
americanos que no Brasil havia muitos espécimes como aquele e que possuíamos um grande número de diferentes tipos de borboletas. Depois disso, procuramos no livro mais informações como seu nome científico e seu significado.

Passada essa etapa de trabalho em grupo, Liz Baird - que ficara assistindo a nosso trabalho de longe, chamou-nos. Pediu para que abríssemos os pequenos círculos e que designássemos um representante para comunicar ao resto da classe os resultados de nossos estudos. Os representantes levantavam-se e se dirigiam ao vídeo para seu relato. A professora balançava a cabeça em aprovação. Quando não compreendia bem alguma frase, pedia que a repetíssemos.

Findas as apresentações, Liz tomou em suas mãos uma caixa contendo um lagarto vivo. Tirou-o de dentro do invólucro e apresentou-o a nós, aproximando a câmera do animal. Começou a descrevê-lo à medida que focalizava partes de seu corpo - as escamas, as patas e os olhos. Enquanto isso ela nos explicava as vantagens dessa aula a distância. Dizia que o uso da tecnologia permitia que animais pequenos pudessem ser observados de perto, com suas características aumentadas pelo zoom da câmera, em completa segurança e numa perspectiva jamais conseguida ao vivo.

Um único animal, explicou ela, poderia servir a toda uma classe e até a várias classes integrantes de um mesmo projeto, não havendo necessidade de se manter em cativeiro diversos espécimes para as aulas.
O uso de animais e plantas para aulas laboratoriais se torna assim, segundo ela, mais higiênico e prudente.

Terminada a aula de história natural, a professora passou a explicar seus procedimentos tecnológicos. Em primeiro lugar, disse ela, é preciso atuar sempre em duplas, aqui no laboratório, pois a coordenadora deve ficar permanentemente no foco das câmeras, sem se virar ou se deslocar pelo ambiente. Assim, enquanto ela se dirige aos alunos, uma monitora ou assistente de produção vai the entregando aquilo de que necessita para a aula. Por outro lado, na sala remota também se fazem necessários dois profissionais - um professor que ajude os alunos no desenvolvimento das atividades e um técnico que se responsabilize pelos equipamentos, pois o ambiente com o qual o laboratório se conecta pode não dispor de equipamentos convenientes e adequados. Qualquer problema que surja deve ser ajustado rapidamente. Essa é a equipe mínima para uma aula que não pretende ser apenas uma palestra transmitida pela rede e que pressupõe atividades laboratoriais ou de treinamento.

O laboratório deve estar bem equipado com computadores e câmeras potentes e a professora virtual deve aprender a manusear os aparelhos de maneira a mostrar detalhes daquilo que apresenta, sejam os olhos de um lagarto, seja o resultado de uma equação. Uma nova postura é exigida dos profissionais da educação. Segundo Liz Baird, o professor de ensino a distância tem que aprender a portar-se 
diante de uma webcam" e lembrar que aquele instrumento é que levará sua imagem para um ponto distante. Tudo isso sem esquecer-se de olhar na tela de seu computador onde aparece a imagem da classe. Como ela diz - precisamos estar atentos ao que cada aluno está fazendo e, se necessário, devemos monitorar a câmera existente na sala remota para focalizar melhor algum aluno distraído ou mal comportado.

Liz Baird explicou que aulas como aquela que ela acabara de realizar conosco já fazem parte do programa de diversas escolas na Carolina do Norte, embora ela não aconselhe mais do que duas aulas por semana através de videoconferência que devem estar mescladas a encontros presenciais e a outras estratégias de comunicação a distância. Perguntada sobre a faixa etária dos alunos desses programas ela concordou que alunos do ensino médio são os mais indicados para esse tipo de experiência.

Ainda apontando outras vantagens da tecnologia que ela apresentava, Baird afirmou ser possível utilizar também textos, sons e imagens extraídos da Internet - Podemos, no meio da aula, mostrar outras salas do Museu também ligadas à Internet.

$\mathrm{O}$ custo não é baixo. A preparação e os equipamentos do Laboratório custam cerca de US $\$ 200.000,00$, custo que pode ser pago com a multiplicação de salas de aula ligadas ao programa. $\mathrm{O}$ resultado, entretanto, é animador - a qualidade da imagem e sua estabilidade são impressionantes. O técnico forneceu aos alunos as especificações técnicas dos equipamentos.

Ao final, continuando a sorrir, a professora despediu-se, mas sua imagem permaneceu na tela até que saíssemos. Mary Ann acompanhou-nos e distribuiu cartões de visitas para contatos futuros.

\section{REPERCUSSÕES}

A experiência com videoconferência fora entusiasmante - a aula se assemelhara em muito com uma atividade presencial, a tecnologia havia oferecido boa qualidade de transmissão, interagir com o vídeo se mostrara uma tarefa simples e cotidiana e as vantagens da metodologia defendidas pela professora-coordenadora eram convincentes. Mas, meu senso crítico de pesquisadora da comunicação inquietava-se.

A primeira inquietação dizia respeito à presença da tela de vídeo como centro protagonista daquela experiência. Apesar de estarmos de frente ao professor, numa atitude que simulava a sala de aula, e da amabilidade da loira Mary Ann, o contato pessoal entre professor e aluno não se dá. Os olhos do mestre jamais encontram os do aluno naquela comunicação tão secreta quanto especial que aqueles que apreciam o magistério sabem reconhecer.

11. Webcam - nome dado às câmeras digitais que conectadas ao computador permitem a transmissão de imagens de um computador a outro. 
O olhar que guia a fala do professor, que alcança os alunos - até o mais distraído - e que os convida para o diálogo não existe na videoconferência.

Ele é substituído pela atração da imagem técnica que tremula diante de nós. $\mathrm{E}$, como telespectadores contumazes, rapidamente nos adaptamos àquela comunicação e fazemos da tela a retina da relação educativa - a membrana que tudo reflete e onde a imagem toma corpo.

$\mathrm{E}$, pensando nessas questões, dei-me conta de que a imagem da professora virtual lembrava-me a de publicidades de sabão em pó, com garotas-propagandas interpretando donas-de-casa e dizendo-nos que com tal sabão a roupa de seu marido ficará mais branca. Nesse momento a câmera deixa o rosto sorridente e satisfeito da modelo e focaliza uma camisa branca reluzente. Ou seria um lagarto? Assim nos conscientizamos de que aquela imagem poderia muito bem não ser de uma professora, que poderia ser de uma modelo que interpreta uma professora. Que poderia ser uma imagem síntese construída no computador, como certos filmes têm demonstrado ser possível. Poderia ser tudo isso sem que deixássemos de aprender, como em um bom documentário, o nome científico do lagarto. Pois temos já uma prontidão para a comunicação televisiva e por computador e todas essas experiências imagéticas nos são familiares.

Assim, se o uso do vídeo possibilita uma maior interatividade, também nos faz mergulhar num universo ima- ginário já codificado, tornando difícil não nos apoiarmos nele para nossas interpretações.

E, em razão disso, por mais que seja benéfico o coeficiente multiplicador dessas

experiências virtuais, não devemos nos esquecer de que a educação é feita também de circuitos integrados que passam por um contato íntimo e por um olhar profundo e que, nesse sentido, toda e qualquer tecnologia deixa sempre a desejar.

Desse modo, entre o entusiasmo e a crítica fica a consideração de que educação a distância é um excelente recurso para todo aluno que por qualquer motivo - distância, falta de tempo e de meios de transporte - não possa participar ao vivo e em cores de uma relação de aprendizado. As novas tecnologias da comunicação oferecem, sem dúvida nenhuma, as melhores alternativas para essa necessidade. Mas, como alternativa para as políticas de educação ou como forma de produção em massa do conhecimento, corre-se o perigo de levar gato por lebre ou sabão em pó em vez de lagartos. 
Resumo: A autora relata sua experiência em um workshop de videoconferência durante a conferência Anual da Associação de Centros de Ciência e Tecnologia, realizada na cidade de Charlotte, na Carolina do Norte (USA), em 2002. O artigo reflete o olhar crítico e ao mesmo tempo entusiasmado da pesquisadora de comunicação em relação a educação a distância. Mostra o quanto o olhar que guia a fala do professor, que alcança os alunos - até o mais distraído - e que os convida para o diálogo não existe na videoconferência. A autora ressalta, ainda, que, embora o uso do vídeo possibilite uma maior interatividade, não devemos nos esquecer de que a educação é feita de circuitos integrados e de um olhar profundo e que, nesse sentido, toda e qualquer tecnologia deixa sempre a desejar.

Palavras-chave: educação a distância, videoconferência, teleconferência, novas tecnologias
(Distance learning - between enthusiasm and critique)

Abstract. The author reports on her experience in a videoconference workshop held during the Yearly Conference of the Science and Technology Center Association, carried out in the city of Charlotte, North Carolina (USA), in 2002. The article reflects the communication researcher's critical and, at the same time, enthusiastic view regarding distance learning. She shows how the look of the eye, which guides the professor's speech and reaches the students - even the most distracted - and invites them for dialogue, does not exist in videoconferences. The author also emphasizes that although the video allows for greater interactivity, we should not forget that education is built in integrated circuits and through a deep look and that, in this regard, any and all technologies always leave to be desired.

Key words: distance learning, videoconference, teleconference, new technologies 